\title{
Changes in the size of the thyroid in patients with benign non-toxic multinodular goiter after radioactive iodine therapy
}

\author{
Iraj Heydari ${ }^{1}$, Maryam Honardoost ${ }^{1}$, Sedighe Moradi ${ }^{1}$, Fatemeh Golgiri ${ }^{1}$, Hamidreza Dehnad $^{1}$, Saba $_{\text {Moradi }}{ }^{2}$, \\ Amir Ziaee*3
}

Received: 2 Sep 2017

Published: 27 Dec 2018

\section{Abstract}

Background: Multinodular goiter (MNG) is regarded as one of the most common causes of hyperthyroidism, particularly in areas of mild-to-moderate iodine deficiency. The present study aims to explore the effects of the radioactive iodine (RAI) therapy on benign non-toxic MNG and evaluate its side effects.

Methods: Patients with benign non-toxic MNG entered the study. Ultrasonography was applied to calculate the percentage of the decrease in the size of the thyroid before and six months minimum after the treatment. Chi-square, Mann-Whiteny-U and T-test were done using SPSS v.18.0 $(\mathrm{p}<0.05)$.

Results: The volumes of the thyroid lobes and nodules decreased significantly due to RAI therapy $(\mathrm{p}<0.001)$. The total volume of the thyroid, volume of the right nodule, and volume of the left nodule decreased by $77.8 \%, 40.7 \%$, and $34.6 \%$ respectively.

Conclusion: According to the results of the current study, RAI therapy is an effective treatment method although it has short-term side effects. This treatment option is recommended for patients with benign non-toxic MNG, notably those who cannot be a candidate for surgery. This treatment affects the size of the thyroid and its nodules significantly and decreases almost all of the complications.

Keywords: Multinodular goiter, Nodule, Radioactive iodine therapy, Thyroid

Conflicts of Interest: None declared

Funding: None

\section{*This work has been published under CC BY-NC-SA 1.0 license.}

Copyright $\subseteq$ Iran University of Medical Sciences

Cite this article as: Heydari I, Honardoost M, Moradi S, Golgiri F, Dehnad H, Moradi S, Ziaee A. Changes in the size of the thyroid in patients with benign non-toxic multinodular goiter after radioactive iodine therapy. Med J Islam Repub Iran. 2018 (27 Dec);32:131. https://doi.org/10.14196/mjiri.32.131

\section{Introduction}

Multinodular goiter (MNG) is regarded as one of the most common causes of hyperthyroidism, particularly in areas of mild-to-moderate iodine deficiency $(1,2)$. This type of goiter usually results from a genetic predisposition and environmental factors, but the most important risk factor for this disease is iodine deficiency $(3,4)$. No definitive treatment for MNG has been developed as yet. Nevertheless, it is necessary to know who really requires surgery for it. Aside from surgery, other medical treatments

\footnotetext{
Corresponding author: Dr Amir Ziaee, ziaee.m@iums.ac.ir

1. Endocrine Research Center, Institute of Endocrinology and Metabolism, Iran University of Medical Sciences, Tehran, Iran

2. Shahid Beheshti University of Medical Sciences, Tehran, Iran

3. Pediatric Growth and Development Research Center, Institute of Endocrinology and Metabolism ,Iran University of Medical Sciences Tehran, Iran
}

include iodine supplements and treatment with levothyroxine as well as radioactive iodine (RAI) (5). It must be mentioned that treatments such as the injection of necrosis-inducing agents, including ethanol, into nodules have also been administered in some trials. Moreover, supplemental iodine has no effect on the size of the gland. As for levothyroxine, it is worth mentioning that it inhibits the development of new nodules at best. However, because of its cardiovascular side effects, especially in elderly people,

$\uparrow$ What is "already known” in this topic:

RAI therapy is widely used for treating toxic MNG which could be more appropriate and superior to the surgical treatment.

\section{$\rightarrow$ What this article adds:}

Considering the significant effect of RAI therapy on the size of the thyroid and its nodules in non-toxic MNG patients, this treatment strategy can be an option for this type of patients, particularly in elderly ones and patients who cannot be a surgical candidate and leads to a decrease in almost all of its complications. 
it is not so safe to consume levothyroxine (1).

Treatment with RAI-131 has been prescribed for symptomatic MNG for more than 10 years. Studies demonstrate that this treatment leads to a decrease in the size of the thyroid by $40 \%$ on average within a year. In the past, these patients were treated with subtotal thyroidectomy. However, the RAI therapy could be more appropriate than and superior to the surgical treatment. The thyroid tissue away from a nodule, in particular, is partly protected in this treatment method. Furthermore, there are a large number of patients who are not suitable surgical candidates due to chronic diseases or because they refuse the surgery. Hyperthyroidism could be seen even in some patients after surgery because part of the thyroid tissue is left in place. Hence, in all of these cases, it seems appropriate to apply a pharmacological method $(3,5,6)$. RAI therapy is widely used for treating toxic MNG now. The oral administration of a single dose can result in the removal of toxic nodules and also a return to the euthyroid state usually within 2 to 4 months (7). However, RAI has not achieved a favorable position in patients with non-toxic MNG yet, and there are some pros and cons of using this treatment in those patients (8-12). Not many studies have been conducted on this, and its long-term results have not been evaluated against those of surgery. Furthermore, the fate of the activity and size of the thyroid after the RAI therapy has not been explored in these Iranian patients.

The aim of this study is to investigate the effect of RIA on the treatment of benign non-toxic MNG and exploration of its effect in Iranian patients.

\section{Methods}

The present research was a cross-sectional study and was approved by the Ethics Committee of Iran University of Medical Sciences. The patients' data were kept confidential, and the results were intended to be published only as a general account. Based on theprevalence of $25-33 \%$ for nodular goiter, $\alpha=0.05$ and $d=0.15$, a total number of
35 subjects were selected (13).

The researchers studied medical records of all MNG patients who had referred to the Institute of Endocrinology and Metabolism from 2009 to 2011 and undergone RAI therapy. The patients who had benign non-toxic MNG entered the study. The percentage of the decrease in the size of the thyroid was calculated by a radiologist using ultrasonography before and, at least, six months after the treatment. Next, according to the research checklist, data, such as age, gender, symptoms of the disease, and treatment side effects, were written down from the records. Finally, the patients' circumstances were analyzed in terms of the variables before and after the treatment. Statistical analysis was done using SPSS v.18.0 by Chisquared test, Mann-Whitney-U, and T-test.

\section{Results}

Totally, 35 patients were selected. All of the patients underwent RAI therapy. The average dose of the RAI was $22.26 \pm 2.84 \mathrm{mCi}$. Table 1 shows the results of paired samples $t$ test for the mean size of the left and right lobes of the thyroid and the nodules in detail.

Subsequent to the calculation of their volumes, their contents before and after the treatment were compared with each other (Table 2). The volumes of both thyroid lobes and their corresponding nodules decreased significantly. The total volume of the thyroid, volume of the right nodule, and volume of the left nodule decreased by $77.8 \%, 40.7 \%$, and $34 \%$ respectively. Furthermore, levels of triiodothyronine (T3), thyroxine (T4), and the TSH in all patients before and after the treatment was calculated. As is observed in Table 2, all thyroid indices, except for T4, had a significant statistical difference compared with those before the treatment using Paired sample t-test.

For further analysis, all differences in the thyroid factors before and after the treatment were measured using Independent-samples t-test and Mann-Whitney U-test and were compared between the two genders $(p<0.05)$. The

Table 1. The size of the left and right lobes of the thyroid and the nodules before and after the RAI therapy

\begin{tabular}{|c|c|c|c|c|c|c|}
\hline & & \multicolumn{2}{|c|}{ Before } & \multicolumn{2}{|c|}{ After } & \multirow[t]{2}{*}{$\mathrm{p}$} \\
\hline & & Mean & SD & Mean & SD & \\
\hline \multirow[b]{2}{*}{ Right thyroid lobe } & Length (mm) & 49.89 & 16.208 & 26.40 & 11.265 & 0.003 \\
\hline & Width (mm) & 30.94 & 14.442 & 17.29 & 6.631 & 0.067 \\
\hline & Length & 50.82 & 18.837 & 29.12 & 14.867 & 0.003 \\
\hline \multirow[t]{2}{*}{ Left thyroid lobe } & Width & 30.56 & 13.951 & 18.62 & 8.616 & 0.018 \\
\hline & Height & 26.65 & 14.304 & 15.853 & 8.5781 & 0.074 \\
\hline \multirow[t]{3}{*}{ Right nodule lobe } & Width & 12.783 & 9.8644 & 6.729 & 5.2050 & 0.032 \\
\hline & Height & 11.986 & 8.5925 & 7.279 & 6.2464 & 0.097 \\
\hline & Length & 13.242 & 9.8654 & 8.740 & 7.5652 & 0.750 \\
\hline \multirow[t]{2}{*}{ Left nodule lobe } & Width & 11.990 & 8.9972 & 6.780 & 6.7324 & 0.044 \\
\hline & Height & 11.623 & 7.4329 & 7.880 & 5.7346 & 0.333 \\
\hline
\end{tabular}

Table 2. The thyroid function tests and the mean volume of each thyroid nodule and lobe before and after the RAI therapy

\begin{tabular}{lccc}
\hline & Before & After & $\mathrm{p}$ \\
\hline T4 & $8.27 \pm 1.10$ & $7.94 \pm 2.36$ & 0.418 \\
T3 & $1.72 \pm 1.46$ & $1.39 \pm 0.24$ & 0.012 \\
TSH & $2.24 \pm 2.29$ & $6.44 \pm 12.02$ & 0.050 \\
Right thyroid lobe volume $(\mathrm{ml})$ & $56.89 \pm 590.14$ & $9.215 \pm 85.0$ & $<0.001$ \\
Left thyroid lobe volume $(\mathrm{ml})$ & $47.66 \pm 428.7$ & $10.223 \pm 110.93$ & $<0.001$ \\
Right nodule volume $(\mathrm{ml})$ & $4.868 \pm 62.13$ & $1.339 \pm 29$ & 0.004 \\
Left nodule volume $(\mathrm{ml})$ & $2.602 \pm 56.90$ & $1.613 \pm 36.13$ & 0.005 \\
\hline
\end{tabular}




\begin{tabular}{|c|c|c|c|c|}
\hline & Total & Male & Female & $\mathrm{p}$ \\
\hline T4 change & $0.53 \pm 2.10$ & $0.053 \pm 2.10$ & $0.68 \pm 2.50$ & 0.186 \\
\hline T3 change & $0.05 \pm 0.008$ & $0.055 \pm 0.088$ & $0.095 \pm 0.211$ & 0.592 \\
\hline TSH change & $4.20 \pm 12.23$ & $2.19 \pm 9.3$ & $5.01 \pm 13.31$ & 0.545 \\
\hline Right thyroid lobe volume change $(\mathrm{ml})$ & $47.682 \pm 53.737$ & $59.902 \pm 54.258$ & $42.794 \pm 53.850$ & 0.403 \\
\hline Left thyroid lobe volume change (ml) & $37.433 \pm 394.91$ & $35.591 \pm 284.03$ & $38.100 \pm 440.18$ & 0.873 \\
\hline Right nodule volume change $(\mathrm{ml})$ & $3.207 \pm 6.002$ & $5.325 \pm 4.941$ & $2.325 \pm 6.275$ & 0.188 \\
\hline Left nodule volume change $(\mathrm{ml})$ & $1.819 \pm 29.81$ & $1.912 \pm 20.45$ & $1.782 \pm 33.36$ & 0.925 \\
\hline
\end{tabular}

Left nodule volume change $(\mathrm{ml})$

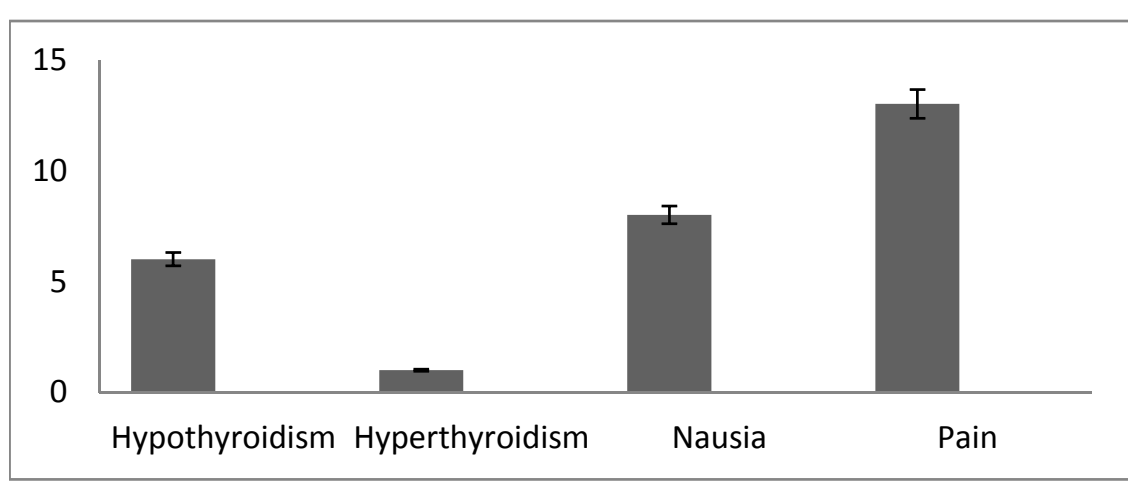

Fig. 1. The prevalence of the side effects caused by the RAI therapy on the patients (\%)

results are shown in Table 3.

None of the changes in the factors between the two genders had a significant statistical difference. In total, 23 patients complained about diverse side effects. The most common side effect was pain in the anterior region of the neck (13 cases). Other side effects are shown in Figure 1.

After the treatment, 6 patients (17.1\%) required levothyroxine. Ibuprofen and prednisolone were prescribed to 6 patients $(17.1 \%)$ and 2 patients $(5.7 \%)$, respectively, just because they felt pain.

\section{Discussion}

Hyperthyroidism continues to be a persistent public health issue worldwide $(5,14)$. Although Radioiodine therapy as a choice in the treatment of hyperthyroidism lasts to gain approval among clinicians, RAI therapy of nontoxic goiters is common in many countries. It is a sensible therapeutic choice, mostly in patients who are older or have a contraindication to surgery. It seems that this method has some benefits such as being non-invasive and having few side effects. The present study revealed that the size of the whole thyroid and its nodules decreased significantly after the RAI therapy. In addition, compared with that before the treatment, the content of T3 decreased significantly and the content of TSH increased significantly (Table 2). However, the content of T4 remained almost unchanged. These results show that, in spite of a decrease in the size of the thyroid and with negative feedback from a decrease in T3, which increases TSH, the level of T4, the main thyroid hormone in the physiological function of the body, is within an acceptable range, which shows the positive effect of RAI on non-toxic MNG. Although most researchers have confined the use of RAI to toxic patients or those with hyperthyroidism, the present study revealed that, despite disagreements, it did not lead to more side effects than the conventional methods do. This group of researchers regards the administration of levothyroxine and performance of surgery as the best treatment methods. Obviously, RAI has fewer side effects than surgical procedures do.

In the current study, the thyroid volume decreased approximately by $77 \%$ and the volumes of its nodules by $40 \%$ on average. There are numerous studies on this (Table 4).

The studies have indicated a decrease by around $40 \%$ in the first year and $60 \%$ in the second year for the thyroid (15-18). It must be mentioned that no study has been carried out yet on the RAI therapy on patients with a colloid cyst or very large goiters with necrotic areas. Moreover, no data about them are available. Due to this, it is usually better to administer this type of treatment under the direct supervision of a physician, which seems so necessary with regard to the rate and type of the side effects. Several review studies have been conducted on this topic, which has

Table 4. The comparison of the rates of the decrease in the thyroid volume between different studies

\begin{tabular}{|c|c|c|c|c|c|c|}
\hline & \multirow[t]{2}{*}{ Reference } & \multirow{2}{*}{$\frac{\text { Age }}{\text { (Years) }}$} & \multirow{2}{*}{$\frac{\text { Follow-up }}{\text { (Years) }}$} & \multicolumn{2}{|c|}{ Thyroid volume (ml) } & \multirow{2}{*}{$\frac{\text { Decrease }}{(\%)}$} \\
\hline & & & & Before & After & \\
\hline Bonema et al. & 10 & 67 & 1 & 311 & 215 & 31 \\
\hline Hegedus et al. & 17 & 56 & 1 & 73 & 43 & 41 \\
\hline Huysmans et al. & 7 & 67 & 1 & 269 & 115 & 40 \\
\hline Le Moli et al. & 15 & 53 & 2 & 82 & 37 & 49 \\
\hline Nygaard et al. & 1 & 57 & 1 & 73 & 29 & 60 \\
\hline Verelst et al. & 16 & $62-83$ & - & 175 & 110 & 39 \\
\hline Wesche et al. & 14 & 48 & 1 & 88 & 49 & 48 \\
\hline Heydari et al. & Present study & 52 & 2 & 104 & 19 & 77 \\
\hline
\end{tabular}


been founded on these studies.

In a study conducted in Germany, Dietien et al. (2006) believe that, considering all aspects, using this treatment method is recommendable. In these studies, they report a decrease by $35-40 \%$ in the size of very large thyroids in patients with MNG (19). As another example, Wesche et al. compared the rate of a marked decrease in the thyroid volume in $64 \mathrm{MNG}$ patients who had received the RAI therapy and levothyroxine. In $97 \%$ of the patients who had undergone the RAI therapy, all symptoms disappeared while only $47 \%$ of the patients having received levothyroxine showed a favorable response (14).

RAI therapy has more benefits than other treatment methods, including levothyroxine and surgery. The most considerable benefit is that iodine can be easily prescribed. It is absorbed only by the thyroid and is easily excreted in the urine. The thyroid undergoes the same processes with RAI that it does with common iodine. Therefore, it does not interfere with the thyroid function, and the physician requires no specific receptor or method for transferring iodine to the thyroid. Moreover, RAI can emit beta and gamma rays simultaneously. It has a halflife of 8 days. Their maximum penetration rate is around 3 $\mathrm{mm}$. As a result, it appears likely that the probability of damage to tissues other than the thyroid is close to zero (20).

There are some studies which have evaluated the effects of RAI on the size of the thyroid. Their total population was around $300(1,14-16,21,22)$. Most of those who were included in these studies were elderly people with very large goiters as well as compressive symptoms or the sudden enlargement of the thyroid. They were not surgical candidates or did not give consent to surgery. In this regard, those studies were similar to the present study. During the studies, all distressing symptoms disappeared. Almost all of the studies reported a decrease in the mean volume by $31 \%$ to $60 \%$, where the most significant decrease usually took place in the first weeks after the treatment.

\section{Conclusion}

RAI therapy is a treatment option for non-toxic MNG, particularly in elderly patients and patients who cannot be a surgical candidate. This treatment can have a significant effect on the size of the thyroid and its nodules, which leads to a decrease in almost all of its complications. Undoubtedly, this treatment has side effects; however, they are for the most part short-term side effects or are easily controllable. Hence, RAI therapy is highly recommended for treating this disease.

\section{Acknowledgments}

The authors are grateful of all staff and participants for their cooperation to collect the data of this study.

\section{Conflict of Interests}

The authors declare that they have no competing interests.

\section{References}

1. Nygaard B, Hegedüs L, Ulriksen P, Nielsen KG, Hansen JM.
Radioiodine therapy for multinodular toxic goiter. Arch Intern Med 1999;159(12):1364-8.

2. Gietka-Czernel M. The thyroid gland in postmenopausal women: physiology and diseases. Menopause Rev. 2017;16(2):33.

3. Kay TW, d'Emden MC, Andrews JT, Martin F. Treatment of nontoxic multinodular goiter with radioactive iodine. Am J Med. 1988;84(1):19-22.

4. Onimode YA, Ankrah A, Adedapo KS. Outcome of radioiodine therapy in a West African population. World J Nucl Med.. 2016;15(1):24.

5. Onimode YA, Ejeh JE, Orunmuyi AT. Adverse Reactions to Radioiodine 131I Therapy of Goiter in West African Tertiary Hospital. Mol Imaging Radionucl Ther. 2016;25(3):128.

6. Sia-Atanacio M, Aileen Y, Mercado-Asis M, Leilani B. Radioactive Iodine Therapy is Effective in Diffuse and Nodular Non-toxic Goiter. Philipp J Intern Med. 2012;49(2):70-3.

7. Huysmans DA, Nieuwlaat WA, Erdtsieck RJ, Schellekens AP, Bus $\mathrm{JW}$, Bravenboer B, et al. Administration of a single low dose of recombinant human thyrotropin significantly enhances thyroid radioiodide uptake in nontoxic nodular goiter. J Clin Endocrinol Metab. 2000;85(10):3592-6.

8. Cappellani A, Zanghì A, Cardì F, Cavallaro A, Piccolo G, Palmucci S, et al. Total Thyroidectomy: the first, the best. The recurrent goiter issue. Clin Ter. 2017;168(3):e194.

9. Nieuwlaat WA, Huysmans DA, van den Bosch HC, Sweep C, Ross $\mathrm{HA}$, Corstens FH, et al. Pretreatment with a single, low dose of recombinant human thyrotropin allows dose reduction of radioiodine therapy in patients with nodular goiter. J Clin Endocrinol Metab. 2003;88(7):3121-9

10. Bonnema SJ, Nielsen VE, Boel-Jørgensen H, Grupe P, Andersen PB, Bastholt L, et al. Recombinant human thyrotropin-stimulated radioiodine therapy of large nodular goiters facilitates tracheal decompression and improves inspiration. J Clin Endocrinol Metab. 2008;93(10):3981-4.

11. Fast S, Hegedüs L, Grupe P, Nielsen VE, Bluhme C, Bastholt L, et al. Recombinant human thyrotropin-stimulated radioiodine therapy of nodular goiter allows major reduction of the radiation burden with retained efficacy. J Clin Endocrinol Metab. 2010;95(8):3719-25.

12. Fast S, Nielsen VE, Bonnema SJ, Hegedüs L. Dose-dependent acute effects of recombinant human TSH (rhTSH) on thyroid size and function: comparison of $0.1,0.3$ and $0.9 \mathrm{mg}$ of rhTSH. Clin Endocrinol . 2010;72(3):411-6.

13. Pinchera A, Aghini-Lombardi F, Antonangeli L, Vitti P. Multinodular goiter. Epidemiology and prevention. Ann Ital Chir. $1996 ; 67(3): 317-25$.

14. Wesche MF, Tiel-v-Buul MM, Smits NJ, Wiersinga WM. Reduction in goiter size by 131I therapy in patients with non-toxic multinodular goiter. Eur J Endocrinol. 1995;132(1):86-7.

15. Le Moli R, Wesche M, Tiel-van Buul M, Wiersinga W. Determinants of longterm outcome of radioiodine therapy of sporadic non-toxic goitre. Clin Endocrinol Oxford. 1999;50:783-90.

16. Vereist J, Bonnyns M, Glinoer D. Radioiodine therapy in voluminous multinodular non-toxic goitre. Acta Endocrinol. 1990;122(4):417-21.

17. Bonnema SJ, Nielsen VE, Hegedus L. Long-term effects of radioiodine on thyroid function, size and patient satisfaction in nontoxic diffuse goitre. Eur J Endocrinol. 2004;150(4):439-45.

18. Aktaș GE, Turoğlu HT, Erdil TY, İnanır S, Dede F. Long-Term Results of Fixed High-Dose I-131 Treatment for Toxic Nodular Goiter: Higher Euthyroidism Rates in Geriatric Patients. Mol Imaging Radionucl Ther2015;24(3):94.

19. Dietlein M, Dederichs B, Kobe C, Theissen P, Schmidt M, Schicha H. Therapy for non-toxic multinodular goiter Radioiodine therapy as attractive alternative to surgery. Nuklearmedizin. 2006;45(1):21-34

20. Clarke S. Radioiodine therapy of the thyroid. Nuclear Medicine in Clinical Diagnosis and Treatment. 1994:833-45.

21. Howarth DM, Epstein MT, Thomas PA, Allen LW, Akerman R, Lan L. Outpatient management of patients with large multinodular goitres treated with fractionated radioiodine. Eur J Nucl Med Mol Imaging. 1997;24(12):1465-9.

22. Ceccarelli C, Brozzi F, Bianchi F, Santini P. Role of recombinant human TSH in the management of large euthyroid multinodular goitre: a new therapeutic option? Pros and cons. Minerva Endocrinol. 2010;35(3):161-71. 